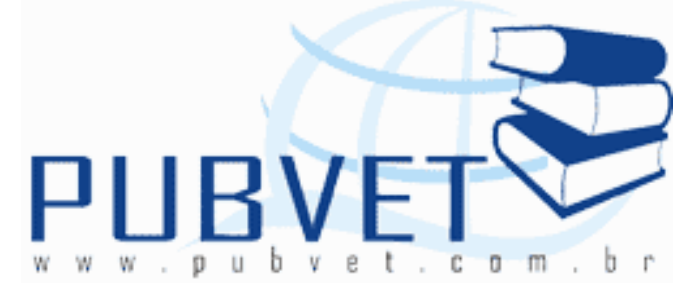

PUBVET, Publicações em Medicina Veterinária e Zootecnia.

\title{
Pesquisa epidemiológica sobre conhecimento de posse responsável em Ilha Solteira-SP
}

Vanessa Veronese Ortunho ${ }^{\mathrm{I}}$, Gabriela de Souza Peres CarvalhoII, Gabriela Costa Baldassi ${ }^{\mathrm{II}}$, Natalia Marques Teixeira ${ }^{\mathrm{II}}$

I Docente da Universidade Estadual Paulista "Júlio de Mesquita Filho" Campus Ilha Solteira, Departamento de Biologia e Zootecnia, e-mail: vanessaverort@yahoo.com.br

${ }^{\text {II }}$ Alunos do primeiro ano de graduação em Zootecnia da Universidade Estadual Paulista "Júlio de Mesquita Filho" Campus Ilha Solteira

\section{Resumo}

Entrevistou-se 100 pessoas moradoras da cidade de Ilha Solteira-SP, entre eles $22 \%$ de homens e $78 \%$ de mulheres. Onde se observou que $95 \%$ dos entrevistados tinham animais e apenas $5 \%$ não, sendo eles cães e gatos das mais variadas raças. Também foi alvo da pesquisa, questões como: o conhecimento dos moradores sobre a importância de vacinar, a importância da posse responsável, a importância de castrar, e a frequência com que eles vacinam, vermifugam, dão banho, usam remédio/coleiras anti-pulgas, passeiam e trocam a água dos animais. Conclui-se que a população carece de informações que expliquem quais são as formas corretas de cuidar de um animal de estimação.

Palavras-chave: cães, gatos, posse responsável. 


\title{
Research about the knowledge of created animals follows the principles of responsible possession in Ilha Solteira - SP
}

\begin{abstract}
Interviewed 100 people living in the Ilha Solteira city, including $22 \%$ of male and $78 \%$ female. Were observed that $95 \%$ of respondents had pets and only $5 \%$ do not. The questions done included about the knowledge of the importance of vaccinating and the importance of have healthy animals. We concluded that population need more information about the care of a pet.
\end{abstract} Keywords: cat, dog, responsible possession.

\section{Introdução}

Atualmente, os cães e gatos são considerados membros da família, recebendo muito carinho, atenção, cuidados médico-veterinário e idas frequentes ao banho e tosa tendo uma vida digna e confortável.

No entanto, infelizmente, existem muitos proprietários que ainda infringem a Lei Federal de Crimes Ambientais 9.605/98 e o Decreto de Lei $n^{\circ}$ 24.645, abandonam seus animais. Estas pessoas alegam motivos banais e inaceitáveis, como sujeira e falta de tempo para cuidar, esquecendo que os animais são seres que sentem dor, medo assim como os seres humanos (CAVICHIOLI, 2012).

O abandono de animais além infringir Lei Federal, caracteriza-se maus tratos, sendo um ato inaceitável, também causa grandes problemas de saúde pública. Assim todo município deveria ter um grande empenho na conscientização das pessoas para que este ato diminua e até se extingue.

Percebendo a necessidade de conscientizar a população surgiu a Lei de Posse Responsável, LEI N.o 13.131/2011, que vigora no Município de São Paulo e esclarece a maneira de como as pessoas devem tratar seus animais.

Nesta lei também está relatado que o órgão municipal responsável pelo controle de zoonoses deveria promover um programa de educação continuada de conscientização da população a respeito da propriedade responsável de 
animais domésticos, podendo para tanto, contar com parcerias e entidades de proteção animal e outras organizações não governamentais e governamentais, universidades, empresas públicas e/ou privadas (nacionais ou internacionais) e entidades de classe ligadas aos médicos veterinários. Este programa deveria atingir o maior número de meios de comunicação, além de contar com material educativo impresso.

Tendo como base alguns princípios de bem estar animal, muitos autores têm divulgado a maneira certa de como criar seu animal, observando alguns itens:

- Cuidados básicos de alimentação: Os animais devem receber uma dieta que atenda as necessidades dele, por isso o oferecimento de ração é o mais indicado. A água oferecida ao animal deve ser de boa qualidade e fresca, por isso deixe a vasilha em local com sombra e troque várias vezes ao dia (CAVICHIOLI, 2012).

- Segurança do animal: Os animais devem ser mantidos dentro de casa, jamais solto na rua. Para os cães, passeios são fundamentais, mas apenas com coleira/guia e conduzido por quem possa contê-lo. Aconselha-se o uso de uma coleira de identificação (CORREIA, 2012).

- Respeite sua casa e a sociedade: recolha e jogue os dejetos (fezes) em local apropriado (CORREIA, 2012).

- Dê banhos regulares em seu cão. E sempre que possível, proteja-o com remédio ou coleira anti-pulgas.

- Saúde física: leve seu animal regularmente ao veterinário para verificar a saúde dele e também para que sejam realizadas as vacinações anuais, controle de vermes, pulgas e carrapatos (CAVICHIOLI, 2012).

- Evite as crias indesejadas de cães e gatos. A castração é a única medida definitiva no controle da procriação e não tem contra-indicações (CORREIA, 2012). 
Por ser muito comum a localização de cães errantes na cidade de Ilha Solteira, interior de São Paulo e por ser uma área endêmica de Leishmaniose realizou-se esta pesquisa que teve como objetivo detectar a porcentagem de pessoas que têm o conhecimento sobre a Posse Responsável, sobre o bem estar animal e de como evitar a disseminação de zoonoses.

\section{Material e Métodos}

Foi realizado um questionário que se baseava nos princípios de Posse Responsável e de bem estar animal: quanto a quantidade de vezes que o proprietário troca a água do animal, quanto a frequência de vacinação e vermifugação e de banhos nos animais, se os proprietários têm conhecimento sobre zoonoses.

Foram entrevistados de forma aleatória 100 moradores da cidade de Ilha Solteira que fica situada no extremo oeste do Estado de São Paulo. Os dados foram tabulados e analisados no programa Excell 2003.

\section{Resultados e Discussão}

Na pesquisa, $78 \%$ dos entrevistados foram do sexo feminino. Apenas $5 \%$ dos analisados não possuíam animais de estimação.

Sobre a importância de vacinar os animais 78 pessoas alegaram conhecer os benefícios de ter um animal vacinado.

Sobre a vacinação da Raiva $43 \%$ dos entrevistados alegaram vacinar seus cães somente na campanha realizada pela prefeitura e reclamaram que neste ano ela não existiu e $7 \%$ dos entrevistados alegaram nunca terem vacinados seus cães contra esta doença.

Quando os proprietários foram indagados sobre a vacinação contra parvovirose, cinomose, leptospirose, coronariovirose...conhecida como V8, V10, V11; 31\% alegaram que somente vacinaram seus cães quando eles eram 
filhotes, $7 \%$ nunca vacinaram seus cães, 55\% vacinam anualmente e $7 \%$ a cada 2 anos.

Quanto a utilização de vermífugos: $12 \%$ dos entrevistados nunca ofereceram este medicamento aos seus animais, $8 \%$ somente quando eram filhotes, $67 \%$ dão 1 vez ao ano e somente $13 \%$ a cada 4 meses.

Entre os entrevistados, 75\% alegaram aplicar anti-pulgas, 85\% não têm animais castrados, $52 \%$ não sabem o que são zoonoses, $20 \%$ nunca saem de casa com seus animais e entre os que deixam seus animais saírem de casa ou que fazem caminhadas com eles, $62 \%$ não deixam seus animais andarem desacompanhados nas ruas enquanto, $20 \%$ deixam seus animais caminharem com coleira e $18 \%$ sem coleira. Quanto a frequência de passeios: $30 \%$ dos entrevistados responderam que seus animais passeiam 1 vez ao dia e $35 \%$ mais que 2 vezes ao dia.

Quanto a frequência de banhos: $23 \%$ das pessoas que responderam 0 questionário alegaram dar banho no seu animal 1 vez por semana e $42 \%$ alegaram que seus cães são lavados 3 vezes por semana.

Sobre a alimentação, $83 \%$ dos entrevistados responderam que oferecem somente ração aos seus animais, 30\% deles trocam a água dos animais 1 vez ao dia, $40 \%$ trocam mais que 2 vezes ao dia.

Sobre as fezes, $65 \%$ dos entrevistados alegaram que sues animais evacuam em casa, $26 \%$ no passeio e $9 \%$ em casa e no passeio. Somente $38 \%$ dos proprietários responderam que recolhem as fezes que seus animais fazem nas ruas.

Foi perguntado também aos proprietários sobre o conhecimento de criar animais sob as condições de bem estar, seguindo algumas das premissas da Posse Responsável e 55\% dos entrevistados responderam nunca terem ouvido falar sobre o assunto enquanto $2 \%$ sabem do significado, mas não seguem. 


\section{Conclusão}

Com este questionário concluiu-se que apenas $43 \%$ das pessoas têm conhecimento e praticam a Posse Responsável. Portanto, é necessário investimentos em políticas públicas que conscientizem a população sobre adotar tais práticas com seus animais, para que a taxa de abandono de animais nas ruas diminua, e assim diminuindo também o risco de transmissão de zoonoses, entre os cães errantes e os seres humanos.

Observando estes resultados, pretende-se no próximo ano desenvolver um Projeto de Extensão na Universidade que tenha como objetivo realizar campanhas de esclarecimento em praças e escolas públicas sobre a importância de adotar as práticas de bem estar animal e de posse responsável e esclarecendo a população sobre os riscos para a saúde pública quando se abandona animais nas ruas.

\section{Referências Bibliográficas}

BRASIL. Lei 9.605, de 1998. Lei Federal de Crimes Ambientais. Disponível em: <http://www.ibama.gov.br/leiambiental/lei.pdf>. Acesso: 20 set 2012.

BRASIL. Decreto Lei no 24645, de 10 de julho de 1934. Dispõe sobre a proteção animal. Disponível em: <http://www.planalto.gov.br/ccivil_03/decreto/1930-1949/D24645.htm>. Acesso em: 25 ag 2012.

CAVICHIOLI, Letícia. Manual de Posse Responsável. Campinas: Gavaa, 2012. Disponível em: <http://www.gavaa.com.br/manual_posse_final_PDF[1].pdf>. Acesso em: 27 out. 2012.

CORReIA, Vinícius. 10 Mandamentos da Posse Responsável. São Paulo: Arca Brasil Associação Humanitária de Proteção e Bem-estar Animal, 2012. Disponível em:

<http://www.arcabrasil.org.br/acoes/posse/mandamentos.htm>. Acesso em: 27 out. 2012.

SÃO PAULO. Lei n. ${ }^{\circ} 13.131$, de 18 de maio de 2001. Dispõe sobre a criação, propriedade, posse, guarda, uso e transporte de cães e gatos no Município de São Paulo. Disponível em: <http://www.prefeitura.sp.gov.br/cidade/secretarias/upload/LeiMunicipal_2001_13131_12535 62346.pdf>. Acesso: 15 set 2012. 


\section{Anexo}

\section{Questionário Posse responsável em Ilha Solteira}

1. Sexo dos entrevistados

( ) Mulher ( ) Homem

2. Possui animal de estimação?

( ) $\operatorname{sim}($ ) não

3. Conhece a importância de vacinar seus animais?

( ) $\operatorname{sim}($ ) não

4. Você levou seu cão para ser vacinado contra raiva?

( ) 1 vez ao ano

( ) filhote

( ) nunca

( ) 1 vez a cada 2 anos

5. Você vacina seus animais contra Raiva?
( ) campanha da Prefeitura
( ) veterinário
( ) depende do ano, pode ser na campanha e também levo no veterinário

6. Você levou seu cão para ser vacinado contra leptospirose, parvovirose, coronavirose, vacina conhecida como V8, V10, V12...?
( ) 1 vez ao ano
( ) filhote
( ) nunca
( ) 1 vez a cada 2 anos

7. Seu animal é vermifugado com que frequência?
( ) nunca
( ) somente quando filhote
( ) 1 vez ao ano
( ) 1 vez a cada 4 meses

8. Você aplica anti-pulgas em seu animal?

( ) $\operatorname{sim}($ ) não 
9. Você tem animais castrados?

( ) $\operatorname{sim}($ ) não

10. Você sabe o que é Zoonose?

( ) $\operatorname{sim}($ ) não

11. Você deixa seu animal passear sozinho?

( ) sim, com coleira

( ) sim, sem coleira

( ) não

12. Você passeia com seu cão?

( ) $\operatorname{sim}($ ) não

13. Quantas vezes ao dia você sai com seu cão ou deixa seu animal sair de casa?

( ) 1 vez dia

( ) 2 vezes

( )mais de 2 vezes

14. Qual é a frequência de banhos de seu animal?

( ) 1 vez por semana

( ) 2 vezes por semana

( ) mais de 2 vezes

15. Seu animal se alimenta de?

( ) ração

( ) comida

( ) os 2

16. Quantas vezes por dia, você troca água do seu animal?

( ) 1 vez dia

( ) 2 vezes

( )mais de 2 vezes

17. Sobre as fezes do seu cão

( )ele faz na rua

( )em casa

( )nos 2 
18. Se ele fizer as fezes na rua, você recolhe?

( ) $\operatorname{sim}($ ) não

19. Você sabe da importância de criar um animal sobre as premissas de bem estar e posse responsável?

( ) sim, e sigo

( ) sim, e não sigo

( ) não 